\title{
New dual-release hydrocortisone tablet for adrenal insufficiency
}

A new hydrocortisone tablet, which contains a coating for immediate drug release and a core for extended release, improved metabolic status in patients with adrenal insufficiency in a phase II/III study.

Patients with adrenal insufficiency treated with hydrocortisone are at increased metabolic and cardiovascular risk. "A cortisol exposure-time profile might be as important as the actual dose for the outcome of patients," says Gudmundur Johannsson, one of the investigators. The study, funded by DuoCort Pharma AB, was an open crossover trial involving 64 adult patients with primary adrenal insufficiency who were randomly allocated to receive the new tablet once daily at $0800 \mathrm{~h}$ or the same daily dose of conventional hydrocortisone three times a day $(0800 \mathrm{~h}$, $1200 \mathrm{~h}$ and $1600 \mathrm{~h}$ ). The crossover phase of the trial consisted of two 12 -week periods.
After 12 weeks, therapy with the dual-release tablet was associated with significant decreases in weight $(-0.7 \mathrm{~kg})$ and systolic and diastolic blood pressure $(-5.5 \mathrm{mmHg}$ and $-2.3 \mathrm{mmHg})$ compared with conventional therapy, although heart rate was increased $(+2.2 \mathrm{bpm})$. Significantly reduced $\mathrm{HbA}_{1 \mathrm{c}}$ levels $(-0.1 \%)$ were observed in patients who received the new tablet, especially if they had concomitant type 1 diabetes mellitus $(n=11 ;-0.6 \%)$.

The new formulation, which received market authorization in the European Union in November 2011, is currently being assessed in a phase IIIb study.

\section{Joana Osório}

Original article Johannsson, G. et al. Improved cortisol exposure-time profile and outcome in patients with adrenal insufficiency: a prospective randomized trial of a novel hydrocortisone dual-release formulation. J. Clin. Endocrinol. Metab. doi:10.1210/jc.2011-1926 